Volume 18, No 4 International Journal of Radiation Research, October 2020

\title{
The evaluation of lung doses for radiation pneumonia risk in stereotactic body radiotherapy: A comparison of intensity modulated radiotherapy, intensity modulated arc therapy, cyberknife and helical tomotherapy
}

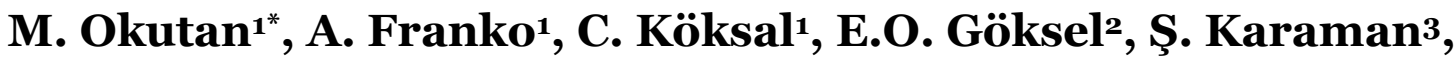 \\ Y. Emre Akpınar4, N. Dağoğlu3, B. Demir5 \\ ${ }^{1}$ Universty of Istanbul, Oncology Institute, Department of Medical Physics, Istanbul Turkey \\ ${ }^{2}$ Universty of Acibadem Mehmet Ali Aydinlar, Vocational School of Health Services, Department of Radiotherapy, \\ Istanbul Turkey \\ ${ }^{3}$ Universty of Istanbul, Oncology Institute, Department of Radiation Oncology, Istanbul Turkey \\ ${ }^{4}$ Universty of Istanbul, Istanbul Medicine Faculty, Department of Radiology, Istanbul Turkey \\ ${ }^{5}$ Universty of Istanbul, Istanbul Science Faculty, Department of Physics, Istanbul Turkey
}

\section{- Original article}

\author{
*Corresponding authors: \\ Murat Okutan, Ph.D., \\ E-mail: \\ mokutan@istanbul.edu.tr \\ Revised: August 2019 \\ Accepted: October 2019 \\ Int. J. Radiat. Res., October 2020; \\ 18(4): 633-640 \\ DOI: 10.18869 /acadpub.ijrr.18.4.633
}

\begin{abstract}
Background: Radiation Pneumonia (RP) is one of the most extensive side effects in Stereotactic Body Radiotherapy (SBRT) of lung cancer. SBRT are performed by means of Intensity Modulated Radiotherapy (IMRT), Intensity Modulated Arc Therapy (IMAT), CyberKnife (CK) or Helical Tomotherapy (HT) treatment methods. In this study, we performed a plan study to determine the plan parameter such as the Mean Lung Dose (MLD), $V_{20 G y}$ Lung Volume and $V_{5 G y}$ Lung Volume in the evaluation of RP risk in the treatment of lung with SBRT. Materials and Methods: Fifteen patients with Lung Cancer who had a tumor diameter of less than $5 \mathrm{~cm}$ and peripheral located were included to this study. Intensity Modulated Radiotherapy, Intensity Modulated Arc Therapy, CyberKnife and Helical Tomotherapy plans were separately created for each patients. For each plan, a total of $54 \mathrm{~Gy}$ dose were given to Planning Target Volume (PTV) in 3 fractions using a dose of 18 Gy per fraction. Results: In each technique for all parameters of PTV and critical organ doses (OAR) meet the required criteria. Total Lung MLD were found as $3.21 \mathrm{~Gy}$ and Total Lung $V_{20 G y}$ Volume were found as $4.05 \mathrm{cc}$, Total Lung $\mathrm{V}_{5 \mathrm{~Gy}}$ Volume were found as $14.06 \mathrm{cc}$ as the lowest value in IMRT-SBRT plan. Conclusion: When treatment plans are evaluated in terms of RP risk, Total Lung MLD, Total Lung $V_{20 G y}$ Volume and Contralateral Lung $V_{5 G y}$ Volume are found the lower in IMRT - SBRT plan than other SBRT techniques. We suggest that IMRT-SBRT irradiation should be preferred in lung radiotherapy in case of high RP risk.
\end{abstract}

Keywords: Radiation pneumonia, stereotactic body radiotherapy, Intensity modulated radiotherapy, Intensity modulated arc therapy, cyberknife, helical tomotherapy.

\section{INTRODUCTION}

Non-small cell lung cancer (NSCLC) covers 75 $-80 \%$ of all lung cancer patients. Approximately $15-20 \%$ of patients are localized and early stage. Generally, the 5-year survival rate is $60-70 \%$ when surgical treatment is performed in these patients. However, a significant proportion of patients with NSCLC are unsuitable for surgery because of the difficulties of lung surgery. In this case, radiotherapy is an important option, especially for patients without distant metastasis. In conventional radiotherapy, the probability of tumor control is $50 \%$ while its 
5 -year survival is $10 \%$ to $30 \%(1,2,3)$. However, for these early stage patients, these results are unsatisfactory because the possibilities for higher treatment doses are limited.

Recently, Stereotactic Body Radiotherapy (SBRT) is an alternative treatment method for patients with early stage NSCLC. SBRT technique increases the local control rate of the tumor. SBRT studies reported a 5-year local control rate of $90 \%$ for the biological equivalent dose with $\mathrm{BED}_{10}>100$ Gy dose value compared with the surgical series $(4,5)$. However, for this high tumor control rate, the application of SBRT requires both precise dose targeting and precise dose shaping. A successful SBRT allows for the protection of critical organs around the tumor by delivering a high dose to the target in single or few fractions. In SBRT of lung cancer, a total of 48-60 Gy dose is usually given to the Planning Target Volume (PTV) in the range of 3 to 6 for prevention of toxicity (6-9).

Like other radiation treatment techniques, SBRT can also cause some side effects and Radiation Pneumonia (RP) is one of the most common toxicities of SBRT. Nevertheless, it has been reported in the literature that SBRT lung therapy cause a lower risk of RP compared to conformal radiotherapy (10-13). On the other hand, late lung toxicity characterized by RP localized on high dose areas develop in most patients (14). SBRT is still in development and dose restrictions used treatment planning are based on most unapproved highly limited clinical data (15). A successful radiation dosimetry can minimize the RP risk. Therefore, as new treatment models evolve, their Dose Volume Histograms (DVH) should be examined in detail and they should be clinically evaluated (16).

Nowadays, SBRT treatments are performed by means of Intensity Modulated Radiotherapy (IMRT), Intensity Modulated Arc Therapy (IMAT), CyberKnife (CK) or Helical Therapy (HT) methods. As far as we know, there are no any study comparing RP risk for lung irradiation among IMRT, IMAT, CK and HT. In present study, we performed a treatment planing study to evaluated the plan parameters and critical organ doses for these techniques.

\section{MATERIALS AND METHODS}

\section{Patient Characteristics}

Fifteen patients with Lung Cancer with a tumor diameter of less than $5 \mathrm{~cm}$ and peripherally located were selected in the study (11 of 15 are NSCLC and 4 of 15 metastatic lung cancer). Patients were between 55 and 81 ages. PTV volumes differed $3.7 \mathrm{cc}$ to $89.6 \mathrm{cc}$, and its mean was 28.76 cc. Detailed patient characteristics were given in table 1 . Instituitional ethics committee approval was obtained before starting this study (Date: 24.11.2017, Registration number: 2017/1357).

Table 1. Patient characteristics.

\begin{tabular}{|c|c|c|c|c|c|}
\hline $\begin{array}{l}\text { Patient } \\
\text { Number }\end{array}$ & Sex & Age & Grade & $\begin{array}{c}\text { Tumor } \\
\text { Localiation }\end{array}$ & $\begin{array}{l}\text { PTV } \\
\text { (cc) }\end{array}$ \\
\hline 1 & $\mathrm{~F}$ & 62 & $\begin{array}{l}\text { Lung Met., } \\
\text { Breast Ca. }\end{array}$ & $\begin{array}{l}\text { R Upper Lobe } \\
\text { Anterior Seg. }\end{array}$ & 28.1 \\
\hline 2 & M & 78 & $\begin{array}{l}\text { Lung Met., } \\
\text { Rectum Ca. }\end{array}$ & $\begin{array}{l}\text { L Upper Lobe } \\
\text { Superior Seg. }\end{array}$ & 89.6 \\
\hline 3 & M & 63 & $\begin{array}{l}\text { Lung Met., } \\
\text { Larenx Ca. }\end{array}$ & $\begin{array}{l}\text { R Upper Lobe } \\
\text { Posterior Seg. }\end{array}$ & 47.32 \\
\hline 4 & M & 58 & $\mathrm{NSCLC}, \mathrm{T}_{2} \mathrm{~N}_{0}$ & $\begin{array}{l}\text { L Upper Lobe } \\
\text { Anterior Seg. }\end{array}$ & 32.4 \\
\hline 5 & M & 80 & $\mathrm{NSCLC}, \mathrm{T}_{2} \mathrm{~N}_{0}$ & $\begin{array}{l}\text { L Upper Lobe } \\
\text { Posterior Seg. }\end{array}$ & 27.4 \\
\hline 6 & M & 60 & $\mathrm{NSCLC}, \mathrm{T}_{1} \mathrm{~N}_{\mathrm{x}}$ & $\begin{array}{l}\text { R Upper Lobe } \\
\text { Posterior Seg. }\end{array}$ & 22.4 \\
\hline 7 & M & 66 & $\mathrm{NSCLC}, \mathrm{T}_{1} \mathrm{~N}_{0}$ & $\begin{array}{l}\text { R Lower Lobe } \\
\text { Posterior Seg }\end{array}$ & 47.1 \\
\hline 8 & $\mathrm{~F}$ & 67 & $\mathrm{NSCLC}, \mathrm{T}_{1} \mathrm{~N}_{0}$ & $\begin{array}{l}\text { R Upper Lobe } \\
\text { Posterior Seg. }\end{array}$ & 12.2 \\
\hline 9 & M & 55 & $\mathrm{NSCLC}, \mathrm{T}_{1} \mathrm{~N}_{0}$ & $\begin{array}{l}\text { R Upper Lobe } \\
\text { Posterior Seg. }\end{array}$ & 41.7 \\
\hline 10 & M & 81 & $\mathrm{NSCLC}, \mathrm{T}_{1} \mathrm{~N}_{0}$ & $\begin{array}{l}\text { L Lower Lobe } \\
\text { Posterior Seg. }\end{array}$ & 3.7 \\
\hline 11 & M & 77 & $\mathrm{NSCLC}, \mathrm{T}_{1} \mathrm{~N}_{0}$ & $\begin{array}{l}\text { R Lower Lobe } \\
\text { Posterior Seg. }\end{array}$ & 21.5 \\
\hline 12 & M & 66 & $\mathrm{NSCLC}, \mathrm{T}_{1} \mathrm{~N}_{0}$ & $\begin{array}{l}\text { R Lower Lobe } \\
\text { Posterior Seg. }\end{array}$ & 20.1 \\
\hline 13 & M & 62 & $\begin{array}{l}\text { Lung Met, } \\
\text { RCC }\end{array}$ & $\begin{array}{l}\text { L Upper Lobe } \\
\text { Posterior Seg. }\end{array}$ & 16.4 \\
\hline 14 & M & 64 & $\mathrm{NSCLC}, \mathrm{T}_{1} \mathrm{~N}_{0}$ & $\begin{array}{l}\text { L Upper Lobe } \\
\text { Posterior Seg. }\end{array}$ & 11.2 \\
\hline 15 & M & 65 & $\mathrm{NSCLC}, \mathrm{T}_{1} \mathrm{~N}_{0}$ & $\begin{array}{l}\text { R Upper Lobe } \\
\text { Posterior Seg. }\end{array}$ & 10.4 \\
\hline
\end{tabular}

Int. J. Radiat. Res., Vol. 18 No. 4, October 2020 


\section{Target Volume Definitions}

All patients were treated with $\mathrm{CK}$ between 2015 and 2018. Apart from CK plans, a new plan for each patient was also created for each treatment modality (IMRT, IMAT and HT) by using the same planning dose prescription and contour slice. Thus, a total of 60 plans were prepared. Image studies for treatment planning were performed in Philips Big Bord 4DCT (Philips Healthcare, Cleveland, OH, USA) using 2 different breath-taking phases and $1 \mathrm{~mm}$ slice thickness. These two CT images were fused. The Internal Target Volume (ITV) and Organ At Risk (OAR) contours were defined on the fused CT slices. PTV was created with $0.5 \mathrm{~cm}$ margin on ITV.

\section{Treatment Plans for IMRT, IMAT, CK and HT}

$6 \mathrm{MV}$ photon beam was used for all treatment methods. The same ITV, PTV and OAR volumes were created for all plans. Thus, the same tumor volumes were irradiated in all plans. As an plan example for all treatment models, figure 1 that showed the axial slices of IMRT, IMAT, CK and HT plans of the same patient was given.

While CK and HT had Flattening Filter Free (FFF) photon rays, photon beam with flattening filter in IMRT and IMAT were used. In each plan, the same dose constraints as shown in table 2 was used for the critical organ volumes. For each plan, a total of 54 Gy doses in 3 fraction were given to the PTV using 18 Gy per fraction. Plans were made so that at least $95 \%$ of the PTV volume was treated with a dose of 54 Gy and at least $99 \%$ of the ITV was received a treatment dose of 54 Gy.

Table 2. Critic organ dose constraints used in treatment planning (RTOG 0915) ${ }^{(17)}$.

\begin{tabular}{|c|c|}
\hline Critic Organs & Dose $_{\max }(\mathrm{Gy})$ \\
\hline Spinal Cord & $18-22$ \\
\hline Esophagus & 30 \\
\hline Heart & 30 \\
\hline Trachea and Bronchi & 30 \\
\hline Great Vessel & 39 \\
\hline LAD & 15 \\
\hline
\end{tabular}

IMRT plans were prepared in the dynamic IMRT mode using Varian Eclipse 15.1 (Varian
Medical Systems, Palo Alto, CA, USA) Treatment Planning System. The dose rate was $400 \mathrm{MU} /$ min. According to the location of the tumor, five coplanar field with different gantry angle were used for each plan.

IMAT plans were prepared using Varian Eclipse 15.1 (Varian Medical Systems, Palo Alto, CA, USA) Treatment Planning System. Dose rate was selected at $600 \mathrm{MU} / \mathrm{min}$. In these plans, two full arc gantry angles were used. In the first arc field, the gantry angles were between $180.1^{0}$ and $179.9^{\circ}$ and the collimator angle was selected as $30^{\circ}$. In the second arc field, the gantry angle was chosen from $179.9^{\circ}$ to $180.1^{\circ}$ and the collimator angle was selected as $330^{\circ}$.

CK plans were prepared using Multiplan version 4.0 (Accuray Inc., Sunnyvale, CA, USA) treatment planning system. The plans were prepared using two fixed collimators depending on PTV size. The dose rate was 800 cGy / MU.

HT plans were performed in the planning system of the HDA (Accuracy Inc., Sunnyvale, CA, USA). Plans were performed using Pitch $=0.123$, Field Width $=1 \mathrm{~cm}$ and Modulation Factor $=1.3$.

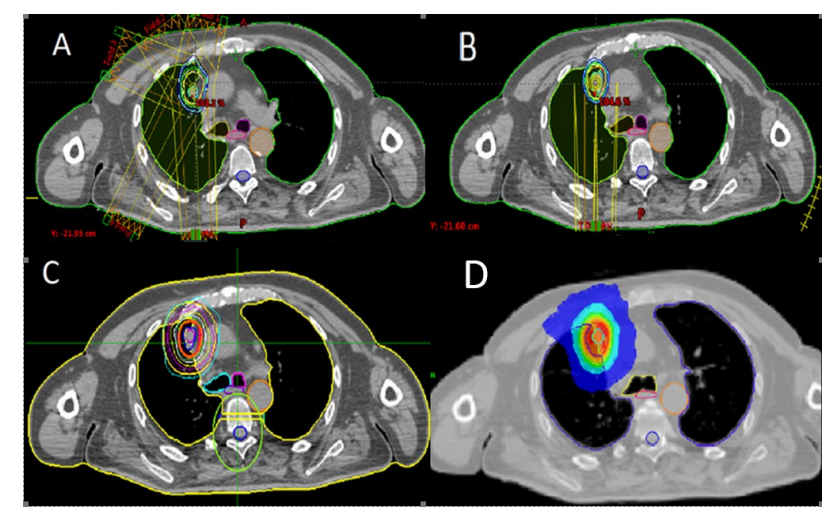

Figure 1. Axial sections of plans in the same patient; A) IMRT B) IMAT C) CK D) HT.

\section{Treatment Plan Parameters for PTV}

The treatment plans parameters for PTV were evaluated by means of parameters in table 3. The maximum dose in PTV is $D_{\max }$, the minimum dose in PTV is $\mathrm{D}_{\min }$ and the average dose for PTV is $D_{\text {mean. The dose of any }}$ percentage of organ volume is indicated by $\mathrm{D} \%$. $\mathrm{Vn}$ is volume of lung receiving at least $\mathrm{n}$ Gy of radiation dose.

The Conformity Index (CI) is calculated as 
follows: $\mathrm{CI}=\left(\mathrm{VT}_{95 \%} / \mathrm{V}_{\mathrm{T}}\right) \times\left(\mathrm{VT}_{95 \%} / \mathrm{V}_{95 \%}\right)$

$\mathrm{V}_{\mathrm{T}}$ is the PTV volume and $\mathrm{VT}_{95 \%}$ is the PTV volume receiving at least $95 \%$ of the prescribed dose. The value of the $\mathrm{CI}$ is necessarily between zero and one. $\mathrm{CI}=1$ represents the ideal situation where the target volume coincides exactly with the treatment volume.

Target dose homogeneity is evaluated through the Homogeneity Index (HI), it is defined as the difference between maximum dose $\left(D_{2 \%}\right)$ and minimum dose ( $\left.D_{98 \%}\right)$ normalized to the prescription dose ( $\left.\mathrm{D}_{\text {prescription }}\right)$.
The Homogeneity Index (HI) is calculated as follows: $\mathrm{HI}=\left(\mathrm{D}_{2 \%}-\mathrm{D}_{98 \%}\right) / \mathrm{D}_{\text {prescription }}$.

A lower $\mathrm{HI}$ value indicates that a plan provides a more homogeneous dose distribution. $\mathrm{HI}=0$ is ideal value.

$\mathrm{R}_{50 \%}$; The ratio of the $50 \%$ isodose volume of the prescribed dose to the PTV volume.

$\mathrm{D}_{2 \mathrm{~cm}}$; The maximum dose at $2 \mathrm{~cm}$ from the PTV in any direction.

Monitor Unit (MU); A measure of radiation "beam-on" time used for medical linear accelerators.

Table 3. $D_{\text {max }}, D_{\text {min }}, D_{\text {mean }}, \mathrm{HI}, \mathrm{Cl}, \mathrm{R}_{50 \%}, \mathrm{D}_{2 \mathrm{~cm}}, \mathrm{MU}$ values for PTV and their statistical results. (The values are the average data of 15 patients).

\begin{tabular}{|c|c|c|c|c|c|c|c|c|c|c|}
\hline TV Parameters & IMRT & IMAT & CK & HT & IMRT-IMAT P & IMRT-CK P & IMRT-HT P* & IMAT-CK & IMAT-HT & $C K-H T P^{*}$ \\
\hline$D_{\max }(G y)$ & 57.84 & 59.10 & 61.65 & 63.76 & 0.044 & $<0.001$ & 0.003 & $<0.001$ & $<0.001$ & 0.011 \\
\hline$D_{\text {mean }}(G y)$ & 55.62 & 56.00 & 60.47 & 57.71 & 0.158 & $<0.001$ & $<0.001$ & $<0.001$ & $<0.001$ & $<0.001$ \\
\hline$D_{\min }(G y)$ & 49.92 & 49.37 & 47.1 & 49.46 & 0.019 & 0.001 & 0.033 & 0.004 & 0.803 & 0.007 \\
\hline $\mathrm{HI}_{5 / 95}$ & 1.05 & 1.06 & 1.17 & 1.10 & 0.237 & $<0.001$ & $<0.001$ & $<0.001$ & .002 & 0.001 \\
\hline $\mathrm{Cl}_{\% 95}$ & 1.89 & 1.39 & 1.43 & 1.51 & $<0.001$ & $<0.001$ & 0.003 & 0.787 & 0.037 & 0.120 \\
\hline $\mathrm{Cl}_{\% 80}$ & 3.55 & 2.26 & 2.28 & 2.43 & $<0.001$ & $<0.001$ & 0.001 & 0.852 & 0.221 & 0.272 \\
\hline $\mathrm{R}$ & 9.56 & 5.77 & 5.26 & 6.14 & 0.001 & $<0.001$ & 0.001 & 0.078 & 0.633 & 0.033 \\
\hline $\mathrm{D}_{2 \mathrm{~cm}}(\%)$ & $\% 85$ & $\% 66.63$ & 655.02 & 657.92 & $<0.001$ & $<0.001$ & $<0.001$ & 0.002 & 0.036 & 0,025 \\
\hline $\mathrm{MU}$ & 4430 & 4624 & 8581 & 11966 & 0.13 & $<0.001$ & $<0.001$ & $<0.001$ & $<0.001$ & 0.001 \\
\hline
\end{tabular}

\section{Lung Dose Parameters}

Since there are to many different perspectives used in the evaluation of RP in the literature, lung parameters are evaluated under 4 main headings as i) Lung minus PTV (Lung PTV) ii) Total Lung iii) Contralateral Lung and iv) Ipsilateral Lung in present study. Besides, as shown in first column of table 4 , there are to many sub-evaluation criteria in the literature such as Lung - PTV V20Gy (cc), Total Lung V30Gy (cc), Contralateral Lung $\mathrm{V}_{10 \mathrm{~Gy}}(\mathrm{cc})$, Ipsilateral Lung $\mathrm{V}_{5 \mathrm{~Gy}}(\mathrm{cc})$. In this study, commonly used parameters in lung evaluation in the literature were calculated by means of treatment planning system and they were separately given in table 4 for each treatment plan.

\section{OAR Dose Parameters}

Although this study focuses on lung doses in terms of RP risk, other critical organ doses are also important. All critical organ doses should be considered when choosing a treatment model. Therefore, in the present study, the doses of all organs evaluated as critical in lung irradiation were also calculated in detail and they were given in table 5 .

\section{Statistical analysis}

For statistical data analysis of treatment plan parameters for PTV in table 3, lung dose parameters in table 4 and OAR doses in table 5, SPSS 23 (Statistical Package for the Social Sciences) program was used. As a first step in SPSS, normalization test was performed to analize if the data were normally distributed. As a result of the normalization test performed in SPSS, when the value of $\mathrm{p}$ is less than 0.05 , the data deviates significantly from the normal distribution. Considering that the distribution was not normal, Kruskal-Wallis, which is one-way analysis of variance and a nonparametric test, was used to find significance, then a Wilcoxon-Mann-Whitney test was used to find the significance between the subject. If the normalization test result was greater than 0.05 , the null hypothesis was

Int. J. Radiat. Res., Vol. 18 No. 4, October 2020 
accepted and the data were considered normal distributed. For normally distributed parameters, a one-way analysis of variance (ANOVA) was calculated to find significance. As a result of this test, when the $\mathrm{p}$ value was smaller than 0.05. Bonferroni test was applied for double comparison because there was a significant difference.

Table 4. Lung dose parameter values and their statistical results for four treatment techniques (The values are the average data of 15 patients).

\begin{tabular}{|c|c|c|c|c|c|c|c|c|c|c|}
\hline Lung Parameters & IMRT & IMAT & CK & HT & $\begin{array}{c}\text { IMRT- } \\
\text { IMAT P* }\end{array}$ & $\begin{array}{l}\text { IMRT- } \\
\text { CK } P^{*}\end{array}$ & $\begin{array}{l}\text { IMRT- } \\
\text { HT P* }\end{array}$ & $\begin{array}{l}\text { IMAT- } \\
\text { CK P* }\end{array}$ & $\begin{array}{l}\text { IMAT- } \\
\text { HT P* }\end{array}$ & $\begin{array}{c}C K-H T \\
P^{*}\end{array}$ \\
\hline Lung-PTV $\mathrm{V}_{20 \mathrm{~Gy}}(\mathrm{cc})$ & 5.13 & 3.49 & 3.55 & 3.67 & 0.019 & 0.021 & 0.018 & 0.576 & 0.534 & 0.443 \\
\hline Lung-PTV $V_{5 G y}(\mathrm{cc})$ & 13.90 & 15.02 & 16.98 & 18.12 & \multicolumn{6}{|c|}{$p>0.05$ (Kruskal-Wallis) } \\
\hline Lung-PTV $D_{\text {mean }}(G y)$ & 3.00 & 2.90 & 3.48 & 3.19 & \multicolumn{6}{|c|}{$p>0.05$ (Kruskal-Wallis) } \\
\hline Lung-PTV 1000cc (Gy) & 1.52 & 2.21 & 3.29 & 2.87 & \multicolumn{6}{|c|}{$p>0.05$ (Kruskal-Wallis) } \\
\hline Lung-PTV 1500cc (Gy) & 0.58 & 0.87 & 2.01 & 1.11 & 0.237 & 0.001 & 0.089 & 0.029 & 0.547 & 0.059 \\
\hline Total Lung MLD (Gy) & 3.21 & 3.31 & 3.87 & 3.51 & \multicolumn{6}{|c|}{$p>0.05$ (Kruskal-Wallis) } \\
\hline Total Lung $\mathrm{V}_{30 \mathrm{~Gy}}(\mathrm{cc})$ & 2.96 & 2.13 & 2.38 & 2.36 & \multicolumn{6}{|c|}{$p>0.05$ (Kruskal-Wallis) } \\
\hline Total Lung $\mathrm{V}_{20 \mathrm{~Gy}}(\mathrm{cc})$ & 4.05 & 5.43 & 4.12 & 4.24 & \multicolumn{6}{|c|}{$p>0.05$ (Kruskal-Wallis) } \\
\hline Total Lung $\mathrm{V}_{10 \mathrm{~Gy}}(\mathrm{cc})$ & 4.49 & 8.77 & 8.64 & 9.40 & \multicolumn{6}{|c|}{$p>0.05$ (Kruskal-Wallis) } \\
\hline Total Lung $\mathrm{V}_{5 \mathrm{~Gy}}(\mathrm{cc})$ & 14.06 & 15.56 & 17.45 & 18.55 & \multicolumn{6}{|c|}{$p>0.05$ (Kruskal-Wallis) } \\
\hline Contralateral Lung MLD(Gy) & 0.61 & 1.18 & 1.29 & 1.71 & 0.001 & 0.001 & $<0.001$ & 0.619 & 0.078 & 0.191 \\
\hline Contralateral Lung $\mathrm{V}_{10 \mathrm{~Gy}}(\mathrm{cc})$ & 0.15 & 0.86 & 0.06 & 0.55 & \multicolumn{6}{|c|}{$p>0.05$ (Kruskal-Wallis) } \\
\hline Contralateral Lung $\mathrm{V}_{5 \mathrm{~Gy}}(\mathrm{cc})$ & 2.98 & 7.82 & 3.91 & 12.00 & 0.001 & 0.418 & 0.001 & 0.003 & 0.101 & $<0.001$ \\
\hline Ipsilateral Lung MLD(Gy) & 5.97 & 5.20 & 6.57 & 5.48 & \multicolumn{6}{|c|}{$p>0.05$ (Kruskal-Wallis) } \\
\hline Ipsilateral Lung $\mathrm{V}_{30 \mathrm{~Gy}}(\mathrm{cc})$ & 5.92 & 4.48 & 4.68 & 4.71 & \multicolumn{6}{|c|}{$p>0.05$ (Kruskal-Wallis) } \\
\hline Ipsilateral Lung $\mathrm{V}_{20 \mathrm{~Gy}}(\mathrm{cc})$ & 10.79 & 8.02 & 8.07 & 8.42 & \multicolumn{6}{|c|}{$p>0.05$ (Kruskal-Wallis) } \\
\hline Ipsilateral Lung $\mathrm{V}_{10 \mathrm{~Gy}}(\mathrm{cc})$ & 18.76 & 16.52 & 16.92 & 18.03 & \multicolumn{6}{|c|}{$p>0.05$ (Kruskal-Wallis) } \\
\hline Ipsilateral Lung $\mathrm{V}_{5 \mathrm{~Gy}}(\mathrm{cc})$ & 23.97 & 23.27 & 31.42 & 24.87 & \multicolumn{6}{|c|}{$p>0.05$ (Kruskal-Wallis) } \\
\hline
\end{tabular}

Table 5. Statistical results of OARs for four treatment techniques. (The values are the average of 15 patients data)

\begin{tabular}{|c|c|c|c|c|c|c|c|c|c|c|}
\hline $\begin{array}{c}\text { OARs } \\
\text { Parameter }\end{array}$ & IMRT & IMAT & CK & HT & $\begin{array}{c}\text { IMRT- } \\
\text { IMAT } P^{*}\end{array}$ & $\begin{array}{c}\text { IMRT- } \\
C K P^{*}\end{array}$ & $\begin{array}{l}\text { IMRT- } \\
\text { HT P* }\end{array}$ & $\begin{array}{c}\text { IMAT- } \\
C K P^{*}\end{array}$ & $\begin{array}{l}\text { IMAT- } \\
\text { HT } \mathrm{P}^{*}\end{array}$ & $\begin{array}{c}C K-H T \\
P^{*}\end{array}$ \\
\hline Heart $D_{\max }(G y)$ & 8.97 & 9.12 & 10.99 & 9.09 & \multicolumn{6}{|c|}{$p>0.05$ (Kruskal-Wallis) } \\
\hline Heart $D_{\text {mean }}(G y)$ & 1.08 & 1.71 & 2.34 & 2.05 & \multicolumn{6}{|c|}{$p>0.05$ (Kruskal-Wallis) } \\
\hline Heart $\mathrm{V}_{5 \mathrm{~Gy}}(\mathrm{cc})$ & 8.55 & 14.28 & 16.08 & 17.77 & \multicolumn{6}{|c|}{$p>0.05$ (Kruskal-Wallis) } \\
\hline Spinal Cord $D_{\max }(G y)$ & 6.89 & 12.90 & 7.01 & 11.41 & 0.001 & 0.724 & 0.044 & 0.002 & 0.351 & 0.011 \\
\hline Spinal Cord $D_{0,25 c c}(G y)$ & 5.95 & 11.89 & 6.09 & 10.76 & 0.001 & 0.468 & 0.029 & $<0.001$ & 0.384 & 0.004 \\
\hline Spinal Cord $D_{1,2 c c}(G y)$ & 5.27 & 10.89 & 5.29 & 10.12 & 0.001 & 0.443 & 0.024 & $<0.001$ & 0.548 & 0.001 \\
\hline Esophagus $\mathrm{D}_{\max }(\mathrm{Gy})$ & 12.10 & 13.43 & 10.10 & 14.50 & \multicolumn{6}{|c|}{$p>0.05$ (Kruskal-Wallis) } \\
\hline Esophagus $D_{\text {mean }}(G y)$ & 1.47 & 1.75 & 2.68 & 2.11 & 0.907 & 0.023 & 0.415 & 0.114 & 0.816 & 0.502 \\
\hline Bronchia $D_{\max }(G y)$ & 8.22 & 7.72 & 7.59 & 8.66 & \multicolumn{6}{|c|}{$p>0.05$ (Kruskal-Wallis) } \\
\hline Tracheal $D_{\max }(G y)$ & 9.65 & 9.30 & 7.65 & 9.38 & \multicolumn{6}{|c|}{$p>0.05$ (Kruskal-Wallis) } \\
\hline Aorta $D_{\max }(G y)$ & 13.49 & 12.91 & 10.33 & 15.29 & \multicolumn{6}{|c|}{$p>0.05$ (Kruskal-Wallis) } \\
\hline$L A D D_{\max }(G y)$ & 2.92 & 3.88 & 4.61 & 4.47 & \multicolumn{6}{|c|}{$p>0.05$ (Kruskal-Wallis) } \\
\hline LAD D ort $(G y)$ & 1.31 & 1.50 & 2.18 & 1.69 & \multicolumn{6}{|c|}{$p>0.05$ (Kruskal-Wallis) } \\
\hline LAD D ${ }^{2}(G y)$ & 2.55 & 3.53 & 4.17 & 4.16 & \multicolumn{6}{|c|}{$p>0.05$ (Kruskal-Wallis) } \\
\hline LAD D $\% 5$ (Gy) & 2.35 & 3.36 & 3.91 & 3.94 & \multicolumn{6}{|c|}{$p>0.05$ (Kruskal-Wallis) } \\
\hline
\end{tabular}




\section{RESULTS}

\section{Evaluation of Treatment Plan Parameters for PTV}

This study is the first direct comparison between IMRT, IMAT, CK and HT treatment techniques. All plans are designed to describe a safe hypofractionated treatment of peripheral lung lesions located at least $1 \mathrm{~cm}$ from the chest wall. The plans are made according to RTOG 0915 (17) protocol. For each plan; $D_{\max }, D_{\min }$, $\mathrm{D}_{\text {mean, }} \mathrm{HI}, \mathrm{CI}, \mathrm{R}_{50 \%}, \mathrm{D}_{2 \mathrm{~cm}}$, MU values and their statistical results are given in table 3 .

\section{Evaluation of Lung Dose Parameters}

For each plans; lung minus PTV (Lung - PTV), Total Lung, Contralateral Lung and Ipsilateral Lung doses values, and their statistics results are given in table 4 .

\section{Evaluation of OAR doses parameters}

For each plans; heart, spinal cord, esophagus, bronchus, tracheal, aortic and left anterior descending (LAD) dose values, and their statistics results are given in table 5 .

\section{DISCUSSION}

Radiation can be used to treat cancer. But, it also causes side effects such as RP. Li et al. (18) reported that the risk of $\mathrm{RP}$ depended on the dose of radiation during 3D conformal radiotherapy. They reported that RP was observed in 7 of 44 patients who were irradiated with a dose below 60 Gy while PR was observed in 22 of 63 patients who were irradiated with a dose above $60 \mathrm{~Gy}$. As in 3D conformal radiotherapy, RP was also an important risk in SBRT. The risk of symptomatic pneumonia was between $9 \%$ and $28 \%$ in published SBRT studies (10-13). One reason for this variability is that some studies do not discriminate between the ipsilateral and contralateral lungs. Guckenberger et al. reported that RP was associated with MLD and irradiated Ipsilateral Lung Volume (12). On the other hand, Ong et al. showed that Contralateral Lung $V_{5 G y}$ significantly correlated with 2-3 grade pneumonia in SBRT patients with NSCLC (13). B. Barriger et al. reviewed the dosimetry records of 251 patients with lymph node-negative Stage I-IIB NSCLC treated with SBRT using a dose of $3 \times 20$ Gy. Their results showed that the rates of clinically significant RP were generaly low with SBRT techniques and overall rate of G2-4 RP in their population treated with SBRT was 9.4\%. They reported that the development of symptomatic RP was correlated with MLD and $\mathrm{V}_{20 \mathrm{~Gy}}{ }^{(10)}$.

The above studies have shown that the risk of $\mathrm{RP}$ is directly dependent on the lung doses and the amount of irradiated volume of the lung. In recent years, radiotherapy treatment modalities have started to show a wide varieties from IMRT to CK. This diversity may cause some difficulties in the evaluation of critical organ doses. Detailed DVH comparisons of these treatment modalities may determine which critical organ receives how much dose. In present study, we perform a plan study to determine the plan parameter such as MLD, $V_{20 G y}$ and $V_{5 G y}$ for the evaluation of $\mathrm{RP}$ risk in the treatment of lung with SBRT.

As can be seen in table 3, all treatment modalities provided the appropriate target coverage. The $\mathrm{R}_{50 \%}$ and $\mathrm{D}_{2 \mathrm{~cm}}$ parameters are used to evaluate the intermediate dose scatter, the fall-off gradient and the conformity of plans made beyond PTV. It was found that the lowest values were in CK with 5.26 and $55.02 \%$ when the value of $R_{50 \%}$ and $D_{2 \mathrm{~cm}}$ was examined. On the other hand, Kannarunimit et al. (7) reported the lowest $\mathrm{R}_{50 \%}$ and $\mathrm{D}_{2 \mathrm{~cm}}$ values in CK technique as in our study. They also reported that Robotic Radiosurgery (CyberKnife-CK) produced a lower RP risk for a scenario of small PTV-OAR overlap and small PTV. This means that less irradiated lung volume creates a low RP risk. Similarly, we determined a less irradiated lung volume in IMRT compared to other SBRT models as shown table 4 ( $p$ value of IMRT versus $\mathrm{p}$ values of IMAT, CK, HT for Lung-PTV $\mathrm{V}_{20 \mathrm{~Gy}}$ (cc)).

Zao J. et al. (19) thoracic analysis of 88 studies with 7752 patients, tumors and dosimetric risk factors for postoperative pulmonary toxicity after SBRT. They concluded that increased age

Int. J. Radiat. Res., Vol. 18 No. 4, October 2020 
and larger tumor size were important risk factors for RP. On the other hand, they concluded that lung treatment planning significantly affects the risk of RP, especially based on Lung $\mathrm{V}_{20 \mathrm{~Gy}}$ and MLD. In our study, Total Lung MLD were 3.21 Gy and Total Lung $V_{20 G y}$ Volume were $4.05 \mathrm{cc}$ as the lowest value at IMRT -SBRT plan as shown in table 4. Due to these low values of our study, IMRT-SBRT may be a treatment model that may reduce the risk of RP.

Guckenberger et al. (12) reported that the Ipsilateral Lung MLD showed a significant correlation with RP risk for tumors smaller than $5 \mathrm{~cm}$ in diameter. Bongers et al. (18) treated 79 patients with $3 \times 18 \mathrm{~Gy}, 5 \times 11 \mathrm{~Gy}, 7 \times 8.5$ Gy and 12x5 Gy dose given according to tumor volumes using IMAT-SBRT. They reported that tumor size and Contralateral MLD are strong predictors of high grade RP. They also emphasized the importance of keeping Contralateral MLD below 3.6 Gy as treatment planning limitation for RP risk. In our study, we determined that Contralateral MLD in 4 treatment techniques was below 3.6 Gy and also the lowest Contralateral MLD was in IMRT-SBRT plans as shown in table 4 ( $p$ value of IMRT versus $p$ values of IMAT, CK, HT for Contralateral Lung MLD (Gy) <0.05).

Apart from Ipsilateral and Contralateral MLD, as can be seen in table 4, we determined that the lowest values for Total Lung MLD and Contralateral Lung $\mathrm{V}_{5 \mathrm{~Gy}}$ Volume were found in IMRT-SBRT technique as $3.21 \mathrm{~Gy}$ and $2.98 \mathrm{cc}$, respectively. Althougth we found the lowest dose in IMAT-SBRT among Ipsilateral Lung $\mathrm{V}_{5 \mathrm{~Gy}}$ Volumes in all treatment plans, there is no statistically significant difference among the Ipsilateral Lung plan parameters.

In this study, apart from lung doses, critical organ doses were also evaluated. From table 5, it is shown that all parameters of OAR in 4 treatment techniques meet the criteria required for a safe treatment and heart, spinal cord and LAD doses were generally lower in IMRT-SBRT technique than other SBRT techniques.

In conclusion, the number of SBRT treatments increase with the development of tumor monitoring methods in early stage lung cancer and increasing survival times. Since the lung is an organ with RP risk depending on the radiation dose and the irradiated volume, it is extremely important that the irradiated volume in SBRT is keep the small. In our study, SBRT plans with four treatment techniques are found to be very similar in terms of both target and critical organ doses. But, Total Lung MLD, Total Lung $\mathrm{V}_{20 \mathrm{~Gy}}$ Volume and Contralateral Lung $\mathrm{V}_{5 \mathrm{~Gy}}$ Volume are found the lowest in IMRT- SBRT plan compared to other SBRT techniques in terms of RP risk. We suggest that IMRT-SBRT irradiation should be preferred in lung radiotherapy in case of high RP risk.

\section{ACKNOWLEDGEMENT}

This study was carried out using the updated TPS (Eclipse 15.1) version under the project "Increasing Tumor Control Ratios in Radiation Oncology and reducing the Side Effects of Volumetric Arc Therapies in Radiation Oncology "(Project ID: 23057).

\section{Conflicts of interest: Declared none.}

\section{REFERENCES}

1. Jochen W,_Baier K, Caragiani E, Tschammler A, Flentje M (2002) Dose, volume, and tumor control prediction in primary radiotherapy of non-small-cell lung cancer. Int $J$ Radiat Oncol Biol Phys, 52: 382-389.

2. Sibley GS, Jamieson TA, Marks LB, Anscher MS, Prosnitz LR (1998) Radiotherapy alone for medically inoperable stage I non-small-cell lung cancer: The Duke experience. Int J Radiat Oncol Biol Phys, 40: 149-154.

3. Kaskowitz L, Graham MV, Emami B, Halverson KJ, Rush C (1993) Radiation therapy alone for stage I non-small cell lung cancer. Int J Radiat Oncol Biol Phys, 27: 517-523.

4. Onishi $H$, Araki T, Shirato $H$, et al. (2004) Stereotactic hypofractionated high-dose irradiation for stage I nonsmall cell lung carcinoma: Clinical outcomes in 245 subjects in a Japanese multiinstitutional study. Cancer, 101:1623-1631.

5. Fakiris AJ, McGarry RC, Yiannoutsos CT, et al. (2009) Stereotactic body radiation therapy for early-stage nonsmall-cell lung carcinoma: four year results of a prospective phase II study. Int J Radiat Oncol Biol Phys, 75: 677-682.

6. Bezjak A, Bradley J, Gaspar LE, et al. (2009) Seamless 


\section{Okutan et al. / Lung doses for radiation pneumonia risk}

phase I/II study of stereotactic lung radiotherapy (SBRT) for early stage, centrally located, non-small cell lung cancer (NSCLC) in medically inoperable patients (RTOG 0813). Trial started February 2

7. Kannarunimit D, Descovich M, Garcia A, et al. (2015) Analysis of dose distribution and risk of pneumonitis in stereotactic body radiation therapy for centrally located lung tumors: a comparison of robotic radiosurgery, helical tomotherapy and volumetric modulated arc therapy. TCRT, 14: 49-60.

8. Lee NY and Terezakis SA (2008) Intensity modulated radiation therapy. Journal of Surgical oncology, 97: 69196.

9. Timmerman R, Paulus R, Galvin J, et al. (2010) Stereotactic body radiation therapy for inoperable early stage lung cancer. JAMA, 303: 1070-1076.

10. Barriger RB, Forquer JA, Brabham JG, et al. (2012) A dosevolume analysis of radiation pnemonitis in non-small cell lung cancer patients treated with stereotactic body radiation therapy. Int J Radiat Oncol Biol Phys, 82: 457462.

11. Borst GR, Ishikawa M, Nijkamp J, et al. (2009) Radiation pneumonitis in patients treated for malignant pulmonary lesions with hypofractionated radiation therapy. Radiotherapy and Oncology, 91: 307-313.

12. Guckenberger M, Baier K, Polat B, et al. (2010) Doseresponse relationship for radiation-induced pneumonitis after pulmonary stereotactic body radiotherapy. Radiotherapy and Oncology, 97: 65-70.

13. Ong CL, Palma D, Verbakel WF, Slotman BJ, Senan S (2010)
Treatment of large stage I-II lung tumors using stereotactic body radiotherapy (SBRT): planning considerations and early toxicity. Radiotherapy and Oncology, 97: 431-436.

14. Huang K, Dahele M, Senan S, et al. (2012) Radiographic changes after lung stereotactic ablative radiotherapy (SABR) can we distinguish recurrence from fibrosis? A systematic review of the literature. Radiotherapy and Oncolog, 102: 335-342.

15. Timmerman RD (2008) An overview of hypofractionation and introduction to this issue of seminars in radiation oncology. Semin Radiat Oncol, 18: 215-222.

16. Atalar B, Dinçbaş FÖ, Aydın S, et al. (2008) The role of dose volume histograms and TGF- $\beta$ in the prediction of radiation pneumonitis: a pilot study. Turkish Journal of Oncology, 23: 109-119.

17. Videtic GMM, Hu C, Singh AK, et al. (2015) A randomized phase 2 study comparing 2 stereotactic body radiation therapy schedules for medically inoperable patients with stage I peripheral non-small cell lung cancer: NRG Oncology RTOG 0915 (NCCTG N0927). Int J Radiat Oncol Biol Phys, 93: 757-764.

18. Li B, Chen SH, Lu HJ, Tan Y (2016) Predictive values of TNF$\alpha$, IL-6, IL-10 for radiation pneumonitis. Int J Radiat Res, 14: 173-179.

19. Zhao J, Yorke E., Li L, et al. (2016) Simple Factors Associated with Radiation-Induced Lung Toxicity after Stereotactic Body Radiation Therapy of the Thorax: A Pooled Analysis of 88 Studies. Int J Radiat Oncol Biol Phys, 95: 1357-1369. 